\title{
UNA APROXIMACIÓN JURÍDICO-FILOSÓFICA A LA MEMORIA Y AL OLVIDO DESDE LA TEORÍA DE LOS DERECHOS FUNDAMENTALES
}

\author{
LEGAL AND PHILOSOPHICAL APPROACHES \\ TO MEMORY AND THE RIGHT TO BE FORGOTTEN \\ FROM A FUNDAMENTAL RIGHTS THEORY
}

\author{
Mónica Martínez LóPez-SÁEZ \\ Universitat de València
}

Fecha de recepción: 9-12-20

Fecha de aceptación: 3-6-21

Resumen: Nuestro mundo digital, basado en el recuerdo como principio categórico y el olvido como defecto anómalo, pone en tela de juicio el principio de que la dignidad humana es el fundamento y el valor superior de todo orden democrático y constitucional, garantizando el derecho de toda persona a definir libremente su identidad y proyecto de vida. En tiempos digitales, los derechos más personalísimos, dispuestos bajo el paraguas de la dignidad y la libertad, requieren un cierto poder de control, una autodeterminación y autonomía informativas. La postura europea ha sido regular el conocido derecho al olvido ante la elaboración automática de perfiles, la compilación y la presentación descontextualizada que las NTIC generan y hacen universalmente accesible en el mundo en línea. Debido a las críticas de su regulación europea y española (2016-2018), el presente artículo analiza, desde un enfoque basado en los derechos fundamentales, la justificación ontológica de este mecanismo de control, para proteger la dignidad humana contra la resurrección perjudicial que producen un clic instantáneo y una memoria digital.

Abstract: Today's world is characterized by digital memory as a categorical principle and oblivion only as the anomalous default. This calls into question the principle that human dignity is the foundation and highest value of any democratic and constitutional order, guaranteeing the right of every person to freely define their identity and life plan. Fundamental rights, arranged under the umbrella of human dignity and freedom, require a certain power of control, a sort of

ISSN: 1133-0937

DERECHOS Y LIBERTADES

DOI: https://doi.org/10.20318/dyl.2022.6518

Número 46, Época II, enero 2022, pp. 177-211 
autonomous and informational self-determination, especially in the context of information and digital technologies. The European stance has been to regulate the so-called right to be forgotten as a personal data control guarantee given the automatic profiling, compilation and decontextualized presentation that NICTs generate and make universally-accessible in the online world. In response to the criticism that the European and Spanish regulation (2016 and 2018) have received, this article analyses, from a fundamental rights-based approach, the rationale behind the need for this mechanism to protect human dignity against the harmful resurrection that an instant click and a digital online memory produce.

Palabras clave: derecho al olvido, dignidad humana, memoria, libre desarrollo, identidad

Keywords: $\quad$ right to be forgotten, human dignity, memory, free development, identity

\section{FUNDAMENTACIÓN TECNO-JURÍDICA: APUNTES INTRODUC- TORIOS SOBRE LA CUESTIÓN DIGITAL Y EL DERECHO AL OLVIDO}

Los avances tecnológicos ocurridos en los últimos años, así como la rápida transformación de la sociedad ante la constante evolución del mundo digital, obligan a plantearse si la regulación jurídica actual de las NTIC, en general, y de la Red, en particular, es eficaz. Estos cambios han ampliado no sólo la difusión universal y la hiperaccesibilidad de datos de carácter personal, sino también los umbrales de la tolerancia pública ante la intromisión en la esfera privada y personal. Es fácil entender la creciente preocupación por los usos potenciales de la información disponible en la red, en una época de acelerado desarrollo tecnológico, en la que la misma herramienta se utiliza prácticamente desde el nacimiento hasta la muerte; una época caracterizada por el acceso libre y directo a la Red y en la que existe un uso masivo, a veces imprudente, de las redes sociales. El progreso tecnológico genera nuevos retos asociados directamente a los derechos clásicos y nuevos derechos personalísimos y, en última instancia, a la dignidad humana, lo cual obliga a ampliar la protección y garantía de los mismos.

Una de estas amenazas es la perennidad de la información que se publica y se comparte en la Red, lo cual supone una permanencia de datos potencialmente perjudiciales para la persona, que son universalmente accesibles con total ausencia de límites espacio-temporales. Como solución a este problema, se ha planteado regular el derecho al olvido digital, entendiéndolo 
como un derecho a suprimir datos personales o desvincular enlaces con los mismos, referidos a hechos pasados o información devenida irrelevante o innecesaria que puedan afectar al libre desarrollo humano: olvido que, por el mero paso del tiempo, no sucede motu proprio en la Red por su infalible memoria, por la visibilidad que otorga a la información en línea, $\mathrm{y}$, finalmente, por el perfeccionamiento de las NTIC en la Red, que perpetúan los hechos pasados de modo generalmente irrestricto. Funciona, por tanto, como un nuevo mecanismo real que garantiza el control de los datos y la identidad, el desarrollo de la personalidad y la dignidad en la Red. Así pues, cabe analizar el derecho al olvido, más allá de una virtud o un principio en la era digital ${ }^{1}$, como un nuevo derecho y garantía, derivado de los derechos de la personalidad y de la autodeterminación informativa y que está estrechamente vinculado al derecho fundamental a la protección de datos.

El marco paneuropeo de protección de datos ha perfilado la forma en la que se procesan y tratan los datos personales en Europa, convirtiéndose en un punto de referencia a nivel mundial en materia de privacidad y protección de la dignidad en tiempos digitales. En un entorno que cada vez depende más del tratamiento de la información personal, la Unión Europea ha garantizado a las personas la posibilidad de controlar de manera más efectiva sus datos personales, a la vez que ha establecido un marco fiable para la innovación y el progreso. El Reglamento general de protección de datos ("RGPD", en adelante) ha sido, sin duda, no sólo la piedra angular de la integración (y transición) digital europea, sino también la herramienta necesaria para la confianza y protección digital. Si bien se ha puesto en duda el enfoque basado en los derechos humanos de la normativa derivada original, por considerarse lo establecido en ella más bien "principios de buena gobernanza" y un enfoque basado en las "obligaciones procedimentales" de los responsables del tratamiento ${ }^{2}$, se podría argumentar que el marco regulatorio de la entonces Directiva y, sobre todo del ahora RGPD, confiere un elenco variado de derechos y garantías además de dar expresión al derecho fundamental

1 V. MAYER-SCHÖNBERGER, Delete. The Virtue of Forgetting in the Digital Age, Princeton University Press, New Jersey, 2009.

2 B. VAN DER SLOOT, “Do data protection rules protect the individual and should they? An assessment of the proposed General Data Protection Regulation", International Data Privacy Law, vol. 4, núm. 4, 2014, 307-325; así como J.A. CANNATACI y J.P. MIFSUDBONNICI, "Data protection comes of age: The data protection clauses in the European Constitutional Treaty", Information E Communications Technology Law Journal, vol. 14, núm. 1, 2005, pp. 5-15. 
a la protección de datos ${ }^{3}$. Esto, Lynskey lo ha considerado suficiente para clasificarlo como un sistema de atribución de derechos (rights-conferring ${ }^{4}$ ) y como un sistema cuyo diseño e interpretación son consistentes con la concepción subyacente de un derecho fundamental (rights-based $\left.{ }^{5}\right)$. Volveremos a esto más adelante.

El 'nacimiento' del llamado derecho al olvido emergió antes que su positivización en el RGPD, pues este derecho cobró su inusual protagonismo entre el 2013 y 2014, a partir de su invocación en la sentencia Google Spain SL ${ }^{6}$. No obstante, una de las novedades más relevantes del RGPD se encuentra precisamente en la consagración específica y el refuerzo de ciertos derechos, que permiten un mayor control sobre el uso de los datos de carácter personal, entre ellos, el archiconocido "derecho al olvido". En este sentido, cabe hacer mención del Considerando 65 del $\mathrm{RGPD}^{7}$, así como de su Considerando $66^{8}$, con alusión explícita a la finalidad del derecho al olvido digital, bautizándolo como tal. Este derecho a obtener la eliminación de datos personales se reconoce y se regula expresamente en el artículo 17 bajo el título Derecho de supresión («el derecho al olvido»). Se podría argumentar que hubiera sido mejor hablar de "suprimir", "desvincular" o "bloquear" que de "olvidar". Unos advierten que todo derecho implica una correlativa obligación y que la obligación a olvidar es un imposible ${ }^{9}$. Otros, sin intención de hacer un juego de palabras, recuerdan que este derecho no está sujeto al paso del tiempo (pudiendo ser aplicado tan pronto como se procesen los datos, sin necesidad

3 Como ha dejado sumamente claro el propio Tribunal de Justicia en numerosas sentencias. Vid., por todas, la primera en establecer que la Directiva de protección de datos debe ser interpretada a la luz del art. 8 de la CDFUE: asuntos acumulados C-465/00, C-138/01 y C-139/01, Rechnungshofv. Osterreichischer Rundfunk, STJUE de 20 de mayo de 2003.

4 O. LYNSKEY, The Foundations of EU Data Protection Law, Oxford University Press, Oxford, 2015, p. 35.

5 Id., p. 36

6 Asunto C-131/12, Google Spain, S.L., v. AEPD y Mario Costeja Gonzalez, STJUE de 13 de mayo de 2014.

7 Cuando afirma que "los interesados deben tener derecho a que se rectifiquen los datos personales que le conciernen y un «derecho al olvido»[...] deben tener derecho a que sus datos personales se supriman y dejen de tratarse [...]".

8 Que apunta que "a fin de reforzar el «derecho al olvido» en el entorno en línea, el derecho de supresión debe ampliarse de tal forma que el responsable del tratamiento que haya hecho públicos datos personales esté obligado a indicar a los responsables del tratamiento que estén tratando tales datos personales que supriman todo enlace a ellos, o las copias o réplicas de tales datos".

9 R. PAZOS CASTRO, "El mal llamado 'derecho al olvido' en la era de Internet", Boletín del Ministerio de Justicia (Estudio doctrinal), núm. 2138, 2015, p. 6.

DERECHOS Y LIBERTADES

ISSN: 1133-0937

Número 46, Época II, enero 2022, pp. 177-211

DOI: https://doi.org/10.20318/dyl.2022.6518 
de que transcurra un lapso temporal) ${ }^{10}$. No obstante, se puede apreciar el peso e influencia que llegó a tener el caso Google Spain, SL para el legislador europeo, pues dedica una disposición a lo que el TJUE llamó precisamente un "derecho al olvido" digital. El artículo 17 RGPD establece la existencia de un derecho y un deber a la supresión de datos personales en determinadas circunstancias. Sentado lo cual, el propio RGPD deja claro que el derecho al olvido digital no es absoluto ni automático ${ }^{11}$. Por lo tanto, llegamos a dos conclusiones principales relativas al orden axiológico y principios fundamentales, asentados en la dignidad de la persona y su necesaria conciliación y ponderación con otros derechos y libertades igualmente fundamentales ${ }^{12}$.

Si bien algunos ponen en duda la novedad del art 17 RGPD, es indiscutible que como mínimo, el elemento más novedoso que establece es precisamente la obligación de los responsables del tratamiento, receptores de una solicitud "bona fide" ${ }^{13}$ de supresión de datos personales, cuando estén obligados a aceptarla, y teniendo en cuenta la tecnología a su alcance, a informar a demás entidades que conozcan o presupongan estén tratando dichos da-

10 S. CARNEROLI, Le droit à l'oubli. Du devoir de mémoire au droit à l'oubli, Larcier, Bruselas, 2016, p. 72.

11 Pues existen unas excepciones para su aplicación: a saber, el ejercicio de la libertad de expresión, el cumplimiento de una obligación legal o misión realizada por motivos de interés público o salud pública, con fines de archivo, de investigación científica, histórica, con fines estadísticos, y en caso de ser necesario para la formulación, el ejercicio o la defensa de reclamaciones.

12 M. MARTÍNEZ LÓPEZ-SÁEZ, "Nuevos perfiles del derecho al olvido en Europa y España", Anuario de la Facultad de Derecho, núm. X, 2017, p. 243: "En primer lugar, el hecho de que exista una protección reforzada para los usuarios a través de un mayor control sobre sus propios datos personales hace que la adopción del nuevo RGPD sea un paso importante hacia la reafirmación de que la dignidad y libertad personal deben tener garantías específicas a través de una autodeterminación informativa que permita a los usuarios colocarse en igualdad de condiciones para enfrentarse a los daños potenciales que brinda la hipermnesia del mundo virtual y el uso que de sus datos se haga en él. Si hacemos una lectura atenta del RGPD, observamos que el derecho al olvido que consagra el artículo 17 supone la facultad o el poder de cada individuo de decidir sobre la facilidad o imposibilidad de acceso de sus propios datos personales. Así pues, el derecho al olvido se enmarca dentro de la dignidad y libertad personal de cada individuo y el respeto a su vida privada e intimidad en el ámbito digital. $Y$, en segundo lugar, el RGPD, como la jurisprudencia a todos los niveles y la doctrina no se cansan de apuntar, nos recuerda que ningún derecho es absoluto y que debe de existir un equilibrio entre derechos e intereses, siendo las llamadas libertades informativas (libertad de expresión, derecho y deber de información, principalmente) un contrapeso, que se vehicula mediante excepciones a la regla general".

13 Así lo consideran D. ERDOS y K. GARSTKA, "The Right to be Forgotten Online within G20 Statutory Data Protection Frameworks", University of Cambridge Faculty of Law Research Paper, núm. 31, 2019, p. 4.

ISSN: 1133-0937

DOI: https://doi.org/10.20318/dyl.2022.6518
DERECHOS Y LIBERTADES

Número 46, Época II, enero 2022, pp. 177-211 
tos $^{14}$. La facultad de actuación jurídica insertada en el contenido de otros derechos ya reconocidos, como el derecho al honor, la intimidad ${ }^{15}$ y la propia imagen ${ }^{16}$, ha servido de justificación para el posicionamiento jurídico sobre el derecho al olvido digital, como nuevo derecho enfrentado a las libertades de información ${ }^{17}$. Se estudia, precisamente, como una de las mayores preocupaciones respecto a las amenazas a la libertad de información en la red, la detección y el control de potenciales manipulaciones, discriminaciones y abusos, situaciones que pueden verse revertidas por un derecho a borrar, bloquear o desvincular información devenida innecesaria, obsoleta o irrelevante por el mero paso del tiempo, limitando el condicionamiento potencialmente negativo del pasado sobre el presente y el futuro.

El ordenamiento jurídico español, hasta hace relativamente poco tiempo, no contaba con una base jurídica específica que reconociera, de manera explícita, u ofreciera la posibilidad de desarrollar, un derecho al olvido digital. La Carta Magna española fue pionera en la constitucionalización de garantías frente a los riesgos inherentes a la revolución tecno-digital de la época (art. 18.4 CE). No obstante, más de cuatro décadas después, resulta incuestionable que la sociedad actual se enfrenta a nuevos riesgos de una "no solo mutada, sino también globalizada, informática" ${ }^{18}$. De tal modo, y como esgrime Rallo, nos enfrentamos a un desafío colosal: el de "constitucionalizar nuevos derechos que satisfagan la demanda social de protección frente a riesgos y amenazas

\footnotetext{
$14 \quad$ Vid. art. 17.2 RGPD

15 J.C. SUÁREZ VILLEGAS, "El derecho al olvido, base de tutela de la intimidad", TELOS, 2014, p. 40.

16 E.R. JORDÀ CAPITÁN, “Un nuevo derecho: el derecho al olvido. Y un viejo conflicto: la colisión de los derechos al honor, la intimidad personal y familiar y la propia imagen de las personas con las libertades de información y de expresión", en E.R. JORDÂ CAPITAN y V. DE PRIEGO FERNÁNDEZ (dirs.) La protección y seguridad de la persona en Internet. Aspectos sociales y jurídicos, Reus, Barcelona, 2014, p. 159.

17 A. BOIX PALOP, “El equilibro entre los derechos del artículo 18 de la Constitución, el «derecho al olvido» y las libertades informativas tras la sentencia Google", Revista General de Derecho Administrativo, núm. 38, 2015, pp. 1-40; y L. COTINO HUESO, "La colisión del derecho a la protección de datos personales y las libertades informativas en la red: pautas generales y particulares de solución", en L. COTINO HUESO (dir.) Libertades de expresión e información en Internet y las redes sociales: ejercicio, amenazas y garantías, Publicaciones Universidad de Valencia, Valencia, 2011, pp. 386-401.

18 M. MARTÍNEZ LÓPEZ-SÁEZ, "Repensando el Derecho Constitucional a la Protección de Datos ante la Mutación de la Informática", en J. MARTÍN CUBAS (ed.), Repensando la Constitución 40 años después, Tirant lo Blanch, Valencia, 2019, p. 158.
} 
[sociodigitales] presentes y futuras ${ }^{\prime 19}$. El derecho fundamental a la protección de datos requiere, al igual que la tecnología de la que nos pretende proteger, de una actividad tuitiva dinámica, reconociendo nuevos derechos y garantías efectivas. Sin lugar a dudas, el derecho al olvido se presenta como uno de estos nuevos derechos y garantías emergentes.

Cabe adelantar la existencia de un reconocimiento informal del derecho al olvido digital, a través del papel pionero de la Agencia Española de Protección de Datos y sus resoluciones relativas a la cancelación de datos personales en multitud de escenarios del entorno digital ${ }^{20}$. No obstante, esto no conllevó una positivización de dichos desarrollos en el terreno normativo hasta una fecha reciente. Por ello, resulta necesario plasmar, a continuación, la evolución normativa del derecho al olvido en el ordenamiento jurídico español, con un doble objetivo: tomar como base el éxito logrado hasta ahora y aprender de los errores pasados, con el fin último de mejorar el sistema de garantías de los derechos en juego. En aras de cumplir con la normativa europea, España se embarcó en una reforma del marco español de protección de datos que culminó con la adopción de la LOPDGDD. En cuanto al derecho al olvido digital, dicha norma ha reconocido, de manera expresa, un derecho al olvido que presenta una serie de peculiaridades y características. Por un lado, el derecho no se ve consagrado en el título y capítulo correspondientes a los derechos del interesado (compuesto por los arts. 12-18 LOPDGDD) sino que se encuentra como "garantía de los derechos digitales" (arts. 79-96 LOPDGDD). La justificación de esta decisión propia del ejercicio discrecional de la técnica legislativa no la encontramos en el texto, y, de hecho, la exposición de motivos parece confundir más que aclarar la necesidad de dividir los derechos y garantías digitales, sobre todo cuando denomina estos últimos "un elenco de derechos [y no garantías] digitales de los ciudadanos conforme al mandato establecido en la Constitución" (énfasis nuestro). Si entendemos, aunque de manera simplista, que en principio los derechos suponen

19 A. RALLO LOMBARTE, “Del Derecho a la Protección de Datos a la Garantía de Nuevos Derechos Digitales" en R. GARCÍA MAHAMUT y B. TOMÁS MALLÉN (eds), El Reglamento General de Protección de Datos un Enfoque Nacional y Comparado. Especial Referencia a la LO 3/2018 De Protección de Datos y Garantía de los Derechos Digitales, Tirant Lo Blanch, Valencia, 2019, p. 137.

20 P. SIMÓN CASTELLANO, El reconocimiento del derecho al olvido digital en España y la UE. Efectos tras la sentencia del TJUE de mayo de 2014, Bosch, Barcelona, 2015, pp. 204-221; y A. RALLO LOMBARTE, El derecho al olvido en Internet. Google versus España, Centro de Estudios Políticos y Constitucionales, Madrid, 2014, pp. 55-135. 
facultades y las garantías son los medios procesales para darles efectividad, parece difícil entender esta distinción entre facultades por parte del legislador español. Esto resulta todavía más confuso si añadimos que la norma, además, reconoce un derecho al olvido para las personas fallecidas, en otro apartado separado (art. 3 LOPDGDD), que permite que los herederos puedan solicitar la supresión de datos personales, extendiendo el ámbito del derecho al olvido y por ende permitiendo un mayor control de los datos de carácter personal incluso tras la muerte, y un derecho propiamente de "supresión" (art. 15 LOPDGDD) mediante el cual se remite al art. 17 RGPD y establece una particularidad en su ejercicio.

Por otro lado, al contrario de lo que sucede con gran parte de los derechos consagrados en ella, la norma no remite el contenido o el ejercicio de dicho derecho a lo establecido por el RGPD, sino que lo divide en dos garantías específicas: un derecho al olvido en búsquedas de Internet (art. 93 LOPDGDD) y un derecho al olvido en servicios de redes sociales y servicios equivalentes (art. 94 LOPDGDD), estableciendo para cada uno su propio desarrollo. En este sentido, el primero hace referencia a un derecho de desindexación o desvinculación de información personal, en el contexto de búsquedas a partir de un nombre cuando dicha información resulte inadecuada, inexacta, no pertinente, no actualizada o excesiva, o hubiera devenido tal por el mero transcurso del tiempo. Similarmente, el segundo hace referencia al derecho de solicitar la eliminación de datos personales facilitados por el interesado o terceros para su publicación en servicios relativos a redes sociales $\mathrm{u}$ otros en el contexto de la sociedad de la información equivalentes bajo las mismas condiciones resumidas anteriormente. Todo lo cual demuestra la pretensión del legislador español: "ha querido hacer una regulación expresa referida a los motores de búsqueda y a las redes sociales, acorde con la jurisprudencia comunitaria, acogiendo sus principios generales, y pese a que estaban también contenidos en el derecho de supresión. No por ello ha de entenderse que se limita a estos responsables $[. . .]^{\prime \prime 21}$.

Con ello, vemos reflejada la manifestación, por antonomasia, de la preocupación que concibió el constituyente español y que ahora desarrolla el legislador debido a la imparable recopilación e intercambio de datos personales, con el consiguiente perjuicio que puede causar su hiperaccesibilidad

21 E. GUICHOT, “El reconocimiento y desarrollo del derecho al olvido en el derecho europeo y español", Revista de Administración Pública, núm. 209, 2019, p. 82.

DERECHOS Y LIBERTADES

ISSN: 1133-0937

Número 46, Época II, enero 2022, pp. 177-211

DOI: https://doi.org/10.20318/dyl.2022.6518 
y "profusa difusión" con el paso del tiempo ${ }^{22}$, en el contexto de motores de búsqueda que, instantáneamente y, de manera organizada, rastrean, indexan y vinculan informaciones personales en la Red. Se ha resumido la situación de partida que produce determinadas situaciones de vulnerabilidad de la siguiente manera: "superado este espejismo de notoriedad otorgado por la presencia de internet, son cada vez más las voces que reclaman la necesidad de unos límites y de dotar al ciudadano de mecanismos de garantía de sus derechos" ${ }^{23}$. El actual desarrollo normativo pretende que toda persona pueda requerir el borrado de los enlaces que contienen datos personales obtenidos en listas de resultados, ofrecidos por motores de búsqueda al teclear el nombre del interesado. Si bien puede parecer que ello implicaría un borrado masivo de información de la Red, es igualmente cierto que la disposición correspondiente hace referencia a que el ejercicio de este derecho no impedirá el acceso a la información publicada en el sitio web (o la fuente original) mediante el uso de otros criterios de búsqueda distintos del nombre del interesado (art. 93.2 LOPDGDD); de este modo, se procura tranquilizar a aquellos que insisten, erróneamente, en que el ejercicio del derecho al olvido implica, necesariamente, una censura o borrado de la historia.

En el contexto de los servicios de redes sociales y demás servicios, todo lo anterior se ha consagrado en el derecho de toda persona a requerir, sin necesidad de aportar motivo alguno (lo que la AEPD comúnmente llama “a su simple solicitud" ${ }^{24}$ ) el borrado de información que hubiesen facilitado ella misma o terceros, para su publicación en dichos servicios. Dicha facultad, no podía ser de otra manera, supone la consiguiente obligación de borrado por parte del prestador de dicho servicio, debiendo proceder a la eliminación, sin dilación, cuando se den las condiciones ya referenciadas (relativas a la falta de adecuación, proporcionalidad, inexactitud, etc.). Se ofrece mayor protección, a través de una mayor facilidad procedimental, a aquellos que, cada vez a edades más tempranas, facilitan sus datos personales, a menudo sin consciencia de los efectos negativos que tiene dicha exposición sobre su presente $\mathrm{y}$, sobre todo, sobre su futuro.

22 A. RALLO LOMBARTE, “Del Derecho a la Protección de Datos a la Garantía..." cit., p. 144.

Álvarez citando a Rallo en M. ÁLVAREZ CARO, Derecho al olvido en Internet: el nuevo paradigma de la privacidad en la era digital, Reus, Madrid, 2015, p. 67.

24 AEPD: El derecho fundamental a la protección de datos, Guía para el Ciudadano, p. 27. Disponible en: http://www.092cr.net/doc/Guia_ciudadana_proteccion_datos.pdf

ISSN: 1133-0937

DOI: https://doi.org/10.20318/dyl.2022.6518
DERECHOS Y LIBERTADES

Número 46, Época II, enero 2022, pp. 177-211 
En los últimos años, la noción de 'derecho al olvido' se ha convertido en un recurso jurídico popular en el contexto de la transformación digital a la vez que en un concepto jurídico indeterminado. A pesar de su indudable repercusión tecno-socio-jurídica, todavía constituye un derecho emergente y una garantía en permanente evolución. Quizás por ello observamos concepciones muy diferentes basadas en el derecho al anonimato, en la efectividad de los principios de la protección de datos a través de la eliminación de datos personales, en revertir lesiones al honor, imagen e intimidad producidas por la difusión de datos personales, o un híbrido de todas. Así, para poder regular correcta y eficazmente este derecho emergente, debemos entender su fundamentación e interpretarlo a través de las teorías y principios filosóficojurídicos más garantistas hacia el respeto de la dignidad de la persona.

\section{LA FUNDAMENTACIÓN ONTOLÓGICA DE UN NUEVO ARS OBLIVIONALIS DIGITALIS}

\subsection{El olvido es elemento inherente a la autoconservación y autode- terminación humana}

¿Qué es la memoria sin el olvido? No hay luz sin oscuridad, bien sin mal, perdón sin ofensa, calor sin frío, lo positivo sin lo negativo, o la vida sin la muerte; rechazando la máxima expressio unius est exclusio alterius, nos decantamos por la máxima de que la existencia de la memoria y el recuerdo necesariamente implican la ausencia del olvido, probando así, su propia existencia. Quizás los dualismos atribuidos a la dialéctica cartesiana y hegeliana sean los culpables de este categórico pensamiento binario, pero la pregunta sigue siendo válida. Una potencial respuesta nos la proporciona el poeta Mario Benedetti en su libro de poemas El olvido está lleno de memoria ${ }^{25}$. Adelantamos que, si bien en su poesía hemos encontrado un lugar predilecto para reflexionar, y dice grandes verdades sobre las injusticias de ciertos actos de amnesia forzada, no concordamos del todo con su incomprensión ante la existencia del olvido o la necesidad de evitar el recuerdo como intento de frenar el remolino destructivo que a veces supone, u ocasiona, la memoria.

De una parte, resulta paradójico, y realmente fascinante, la persistencia con la que el ser humano, a lo largo de la historia de la humanidad, en un

25 M. BENEDETTI, El olvido está lleno de memoria, Visor, Madrid, 1995. 
plano colectivo, ha tratado de mejorar su capacidad de recordar información y conmemorar eventos significativos, y al mismo tiempo, en un plano individual, impelido por el temor de su incapacidad de olvidar (pues "nada graba tan fijamente alguna cosa a nuestra memoria como el deseo de olvidarla" ${ }^{26}$ ), se ha visto impulsado a tratar de forzarlo, siendo, a veces, la abstención del recuerdo una cuestión de supervivencia. De hecho, el principio de autoconservación es parte inherente de la biología humana, y, de nuevo, paradójicamente, el propio cerebro utiliza la supresión como medida contra una mayor destrucción. Los estudios pioneros en el campo de la Biología y la Neurociencia, han estudiado los mecanismos moleculares y celulares del olvido activo que realiza nuestro propio cerebro, desbancando el mito de que el olvido es un proceso pasivo: resulta que el cerebro está ingeniosamente diseñado para olvidar y forzar el olvido, y esto es algo positivo para el conjunto de su sistema ${ }^{27}$.

De otra parte, podría parecer una tarea sumamente osada el aventurarnos en el estudio del olvido, y defenderlo como garantía de los derechos fundamentales en el momento actual en el que se ha dejado de sobra claro, a nivel mundial, que ciertos actos no gozan ni de perdón ni de olvido y que el borrado de la historia supone la peor profanación de la preservación de certidumbres y, en última instancia, de las verdades, de la humanidad. Desde luego, el entorno sociopolítico actual, caracterizado por el rechazo absoluto a la censura, caracterizado por los discursos de la memoria histórica y por las demandas de que las transgresiones totalitarias de la historia y los crímenes de guerra y lesa humanidad sean perseguidos y castigados, no ofrece las condiciones más favorables para la tranquila contemplación, exaltada defensa, o al menos la apertura a la aceptación de un derecho al olvido. No obstante, ni los derechos, ni las posiciones teóricas son absolutas. A tal respecto, encontramos muy esclarecedoras las reflexiones de Sánchez Martínez, pues para el ejercicio libre y pleno de los derechos fundamentales, entre los que cita la intimidad y el libre desarrollo de la personalidad, la persona, en ciertos momentos necesita recordar y, en otros, olvidar, y que, en la construcción del futuro es necesario, a veces desenterrar y a veces enterrar el pasado,

26 Michel de Montaigne, citado por M. ROSSI, La Memoria Transgeneracional. Peter Lang, Oxford, 2016, p. 289.

27 Todo ello se resume en L. GRAVITZ, “The forgotten part of memory. Long thought to be a glitch of memory, researchers are coming to realize that the ability to forget is crucial to how the brain works", Nature, 24-07-2019. Disponible en: https://www.nature.com/articles/ d41586-019-02211-5. 
en algunas ocasiones, es necesario conocer y en otras, más bien desconocer y, según ella, "aunque ni el recuerdo ni el olvido pueden imponerse, sí se puede facilitar o dificultar la difusión de ciertos acontecimientos o datos para hacerlos presentes o ausentes en la formación de la memoria colectiva y desde ahí hacer más o menos posible el recuerdo o el olvido" 28 .

\subsection{Una aproximación multicultural al perdón, el olvido y la 'impermanencia'}

Dicho lo cual, tampoco podemos ignorar que las grandes religiones mundiales se han erigido sobre la base del perdón, el olvido y la premisa de la 'impermanencia'. La mayoría de ellas del mundo incluyen enseñanzas sobre el perdón. Así, el Judaísmo pone como obligación moral el perdonar cuando hay arrepentimiento sincero (la llamada teshuva como acto piadoso o de expiación) y dedican un día especial, el Yom Kippur, para hacer un esfuerzo colectivo e individual para realizar la teshuva. En el Cristianismo, el perdón juega un papel principal, no sólo como modelo vital y esfuerzo personal en las relaciones con el prójimo, sino como obligación moral para estar en paz con Dios, sobre todo cuando se han cometido conductas contrarias a la moral cristiana. De una parte, y quizás la lección más importante que proporcionan las enseñanzas cristianas (palmaria en su segundo mandamiento) es una suerte de olvido de uno mismo para amar y servir al prójimo, conectándose con el despojo del egoísmo y la apertura hacia la abnegación y la humildad; ambas producto del olvido de uno mismo ${ }^{29}$.

Por otra parte, el arrepentimiento y su subsiguiente perdón por un todopoderoso y misericordioso Dios van necesariamente ligados al olvido e implican una suerte de tabula rasa; idea que vemos es uno de los leitmotivs de la Biblia, que pivota alrededor de la Redención, el perdón universal de hechos del pasado, presente y futuro ${ }^{30}$. En el Islamismo, la propia palabra

28 M.O. SÁNCHEZ MARTÍNEZ, “Un derecho de palabras y silencios”, Anuario de Filosofía del Derecho, vol. XXXV, 2019, pp. 195-196.

29 Aunque se tiende a interpretar, de manera equivocada, la humildad y el servicio cristiano a través de ese "auto olvido", estos no implican el menosprecio de uno mismo, sino, como matiza C.S. Lewis "no es pensar menos de ti mismo, es pensar menos en ti mismo" (el texto original es de 1947, pero salió publicado en The Weight of Glory (1949), Harper Collins, New York, 2001, pp. 181-183; y C.S. LEWIS, Essay on Forgiveness (1947), Macmillan, London, 1960, pp. 1-2).

30 Con relación a la todopoderosa misericordia de Dios demostrada a través de un olvido ciego tras un acto de contrición y de acercamiento destacamos los siguientes extractos

DERECHOS Y LIBERTADES

ISSN: 1133-0937

Número 46, Época II, enero 2022, pp. 177-211

DOI: https://doi.org/10.20318/dyl.2022.6518 
Islam, derivada del término Salem, significa 'paz', constituyendo el perdón un requisito previo para la auténtica paz eterna ${ }^{31}$. En análoga línea, las enseñanzas sobre el olvido y la mutabilidad se ven bien reflejadas en las religiones orientales del mundo. En el Budismo, existe la llamada annica (impermanencia) como canon y doctrina esencial que, a grandes rasgos, afirma que toda existencia es transitoria, evanescente e inconstante, quedando todo expuesto a un continuo nacimiento, cambio, decadencia y destrucción; la annica se incluye como la primera de las tres fases o marcas de la existencia hacia la iluminación y sus premisas han sido intensamente adoptadas por la filosofía y estética zen japonesa (los conocidos mujō y Mono no aware). De manera similar, en el Hinduismo, el equivalente del término budista, la anitya, también se construye en sus principales textos espirituales. Desde luego, el perdón, que va, necesariamente de la mano del olvido, tiene efectos positivos en el bienestar de la persona, mantiene el orden social, fomenta las relaciones sociales, y, lo más importante de todo, es una fuerza liberadora para el espíritu y rehabilitadora para la dignidad humana. De igual manera, la filosofía oriental sobre la impermanencia, sobre todo su versión japonesa, tiene como fin último, a través de un entendimiento de que todo es transitorio y mutable, lograr la felicidad.

El refrán popular reza "más vale pedir perdón que pedir permiso" y Kant proclamaba que la razón necesita libertad ${ }^{32}$. Pues bien, por qué no seguir algo que tenemos tan interiorizado también en nuestra faceta vital digital: vivir y expresarse en libertad, abrazando esa espontaneidad que a veces caracteriza nuestras palabras y actos, y, en caso de arrepentimiento, de haber llegado a cierta madurez, o simplemente en caso de haber cambiado de parecer e identidad, con la misma libertad poder enterrar actos de libertad

bíblicos: "Porque seré propicio a sus injusticias, Y nunca más me acordaré de sus pecados y de sus iniquidades" (Hebreos 8:12-13); y "El volverá a tener misericordia de nosotros; sepultará nuestras iniquidades, y echará en lo profundo del mar todos nuestros pecados" (Miqueas 7:19). Con relación a la importancia de dejar el pasado atrás: "No os acordéis de las cosas pasadas, ni traigáis a memoria las cosas antiguas. He aquí que yo hago cosa nueva; pronto saldrá a luz; ¿no la conoceréis? Otra vez abriré camino en el desierto, y ríos en la soledad" (Isaías 43:18-19); "Hermanos, yo mismo no pretendo haberlo ya alcanzado; pero una cosa hago: olvidando ciertamente lo que queda atrás, y extendiéndome a lo que está delante" (Filipenses 3:13).

31 Según el Corán aquellos que perdonan y mantienen la justicia son recompensados por Allah.

32 Vid. los textos destacados de Kant en J. ECHEGOYEN OLLETA, Historia de la Filosofía. Volumen 2: Filosofía Medieval y Moderna, Editorial Edinumen. Disponible también en: https:// www.e-torredebabel.com/Historia-de-la-filosofia/Filosofiamedievalymoderna/Kant/Kant-Libertad.htm 
pasados. Mejor pecar por excederse en la libertad que pecar de esconderse en la autocensura.

\subsection{Del 'oblivionismo' científico en sentido amplio al 'oblivionis- mo' digital en sentido estricto}

Intentamos, además, ampararnos en el hecho de que este trabajo acomete el estudio de otro tipo de perdón y de olvido, uno que despliega sus efectos en el entorno virtual, y lo hace, precisamente, no solo para permitir el libre desarrollo de la identidad y de la autonomía individual, sino también, y sobre todo, para proteger aquellos colectivos de personas que son víctimas directas de conductas deplorables, o sufren los daños colaterales que conlleva el confiar plenamente en la Red; es decir, no pretende resguardar a los sujetos que causan dolor y angustia, sino a los que lo padecen. Por último, encontramos cobijo científico en tratar el controvertido tema del olvido en cuanto este es, tal vez para sorpresa de algunos, parte innata del funcionamiento de cualquier ciencia del conocimiento (aunque es especialmente cierto en las ciencias puras como la química, las matemáticas o la computación). En el ámbito de la investigación científica, en general, se recurre constantemente al olvido en tanto en cuanto es necesario rechazar información desactualizada, superflua o irrelevante, sobre todo si no tiene cabida en el progreso científico o ayuda a avanzar el conocimiento. Este cupo, no de sesgo sino de olvido, es requisito básico de lo que algunos han llamado el "oblivionismo" científico ${ }^{33}$. Al mismo tiempo, abogamos precisamente por un derecho al olvido que no se identifique con la censura de contenidos, en tanto en cuanto se basa en la desvinculación de información personal en la Red, y no de su fuente original (a no ser, por supuesto, que en esta se haya tratado o esté tratando, con incumplimiento de la normativa de protección de datos y de los principios que la estructuran). Se trata, pues, de evitar que la máxima que expone Osten ("vivimos del pasado y perecemos por el pasado" ${ }^{34}$ ) sea el reflejo y la penitencia de lo que nos ha tocado vivir en la era digital.

El desarrollo y perfección de las NTIC y los sistemas informáticos específicos de la Red, así como su adopción y adaptación a todas las facetas de la

33 H. WEINRICK, Lethe: the Art and Critique of Forgetting (trad. S. RENDALL), Cornell University Press, Ithaca, 2004, p. 214; o, más recientemente, M. VALENTINUZZI, “Oblivion Phenomenon in Science" IEEE Pulse, vol. 10, núm. 6, 2019, pp. 20-22.

34 M. OSTEN, La memoria robada. Los sistemas digitales y la destrucción de la cultura del recuerdo. Breve historia del olvido (trad. M.A.VEGA) Ediciones Siruela, Madrid, 2008, p. 39. 
vida, ha reconfigurado el significado y el uso de determinados términos, incluyendo los que pudieran parecer exentos de necesidad de aclaración; entre ellos, indudablemente, se encuentra el término de permanente actualidad: el 'olvido'. El Diccionario de la Lengua Española de la RAE, en su primera acepción define el olvido como la "cesación de la memoria que se tenía", y lo matiza definiendo echar al (o en) olvido "dejar de retener en la mente" ${ }^{35}$. La propia Biología nos proporciona ejemplos paradigmáticos que aluden a la otra faceta del olvido: esa cesación devenida en descarte o destrucción. La persona, sin entrar todavía en aspectos psicológicos o identitarios, es completamente distinta a nivel biológico por el mero paso del tiempo pues todas las células humanas se destruyen y se renuevan cada siete a diez años; en el caso de las células principales de la epidermis este proceso ocurre cada dos semanas. En otras palabras, la destrucción, mejora y el renacimiento del ser humano es un proceso natural y necesario para su propia existencia y bienestar.

Es bien sabido que el olvido ha estado tradicionalmente vinculado a la Neurología y a la Psiquiatría, como ciencias de la salud que han estudiado y evaluado el binomio memoria-olvido en el contexto del trauma (bien con respecto a la amnesia postraumática o bien con respecto a trastornos postraumáticos caracterizados por la superestimulación memorística) ${ }^{36}$ o en relación con el deterioro cognitivo propio de enfermedades neurodegenerativas como el Parkinson o el Alzheimer. Con respecto a las primeras, destacamos el estudio del trastorno de estrés postraumático que hace Schönenberg, que además de explorar la limitada capacidad de la memoria humana, sostiene que el propio cerebro descarta y suprime aquella información que no considera crítica e imprescindible, para dar cabida a nuevos conocimientos y muestra los beneficios del olvido para la recuperación de ciertas experiencias

35 Olvido. (s.f.). Diccionario de la Real Academia Española (23 ${ }^{\mathrm{a}}$ ed.). Disponible en: $h$ ttps:// dle.rae.es/olvido

36 Vid., por todas, las contribuciones que se encuentran en M. LINDEN y K. RUTKOWSKI, K. (eds.) Hurting Memories and Beneficial Forgetting Posttraumatic Stress Disorders, Biographical Developments, and Social Conflicts, Elsevier, London, 2013. Para estudios concretos de los beneficios psicológicos del olvido, sea para aumentar la creatividad o para disminuir los efectos emocionales de eventos traumáticos, vid., por todos, B.C. STORM y T.N. PATEL, "Forgetting as a Consequence and Enabler of Creative Thinking", Journal of Experimental Psychology: Learning, Memory, and Cognition, Vol. 40, núm. 6, 2014, pp. 1594-1609; y C.R. BREWIN, "Remembering and forgetting” en M. FRIEDMAN, T. KEANE y P. RESICK, (eds.), Handbook of PTSD: Science and Practice, Guilford Press, New York, 2014, pp. 200-218.

ISSN: 1133-0937

DOI: https://doi.org/10.20318/dyl.2022.6518
DERECHOS Y LIBERTADES

Número 46, Época II, enero 2022, pp. 177-211 
vitales ${ }^{37}$. Con respecto a las segundas, resultan particularmente interesantes los estudios sobre esta última enfermedad neurodegenerativa, conocida como la 'enfermedad del olvido', que demuestran las ventajas y efectos positivos de una supresión orientada y controlada (directed forgetting) de la información o recuerdos 'irrelevantes', para dejar paso a los 'relevantes' ${ }^{38}$.

Se ha hablado, en variados contextos, incluso del olvido como una forma de muerte, el paso necesario hacia la muerte o la muerte en sí misma ${ }^{39}$. Ahora bien, queremos realizar dos puntualizaciones. Primera, que, en ocasiones, vivir únicamente del presente supone conquistar las ansiedades de la vida, pues vivir en el momento nos libra de las cadenas pesadas del pasado ${ }^{40}$. Por ello, nos conformamos a medias con lo que dicen algunos: que la memoria es la base de nuestra personalidad, que somos lo que hacemos, lo que decimos y lo que nos pasa ("somos en cada momento la memoria de nosotros mismos" $\left.{ }^{41}\right)$. Nuestro pasado indudablemente nos condiciona, pero no nos determina, y es parte de la búsqueda individual de cada uno averiguar quién es; las respuestas, en cualquier caso, se hallan en el presente ${ }^{42}$. Segunda, no

37 M.SCHÖNENBERG, "Pathological Modes of Remembering: The PTSD Experience", en M. LINDEN y K. RUTKOWSKI (eds.), Hurting Memories and Beneficial Forgetting Posttraumatic Stress Disorders, Biographical Developments, and Social Conflicts, Elsevier, London, 2013, pp. 71-82.

38 M. EL HAJ, "Memory suppression in Alzheimer's disease”, Neurological Sciences, vol. 37, 2016, pp. 337-343.

39 En palabras de Gabriel García Márquez (“la muerte no llega con la vejez sino con el olvido"). Asimismo, destacamos la interpretación que hace Marín del mitológico río Lete: "el río del olvido, y en el adjetivo «letal», lo que produce la muerte. Que el olvido sea letal y lo que causa la muerte significa que el olvido es la forma del tránsito del mundo de los vivos al de los muertos, el río en el que hay que dejar cuanto se traía hasta quedar despojado de uno mismo para ser casi invisible, una sombra irreconocible. De ahi que la muerte se presente como una transfiguración por desvanecimiento que hace perder la visibilidad, esto es, el cuerpo, y la identidad, es decir, los recuerdos". Vid. H. MARÍN, "Muerte, memoria y olvido”, Thémata. Revista de Filosofía, núm. 37, 2006, pp. 312-313.

40 Tal vez Paulo Coehlo lo haya dicho mejor en La Quinta Montaña (1996) y en Aleph (2011): el regalo de la vida está en vivir en el momento, en el presente, y en caso de pasados que nos dejan insatisfechos, el olvido, la reinvención y el presente son la solución.

41 J.M. SEGOVIA DE ARANA, "Memoria y olvido" Anales de la Real Academia de Ciencias Morales y Políticas, núm. 80, 2003, p. 633.

42 Inspirados por el remake de la película Total Recall (2012) transcribimos la que consideramos la escena más significativa: “QQué es lo que quieres? [...] Quiero recordar [...] ¿Por qué? [...] Para poder ser yo mismo [...] Es la búsqueda de cada hombre para averiguar quién es realmente, pero la respuesta a eso está en el presente, no en el pasado [...] Pero el pasado nos dice en quién nos hemos convertido [...] El pasado es una construcción de la mente. Nos ciega. Nos engaña para que lo creamos. Pero el corazón quiere vivir en el presente. Mira allí. Encontrarás tu respuesta".

DERECHOS Y LIBERTADES

ISSN: 1133-0937

Número 46, Época II, enero 2022, pp. 177-211

DOI: https://doi.org/10.20318/dyl.2022.6518 
podemos equiparar las circunstancias que rodean la memoria (y olvido) humano con la memoria (y "olvido") digital, por la simple pero aplastante razón de que el primero está fuera de nuestro control, es decir, nos viene impuesto; en cambio, en el segundo, somos nosotros, de manera informada, consciente y voluntaria los que decidimos dejar algo en el olvido, y usar una libertad $^{43}$, autonomía y dignidad de las cuales la imperfecta memoria humana, en general, y la plagada por vacíos y lagunas, en particular, nos despojan. Concomitante con estas ideas, resulta igualmente triste y angustioso que la persona tenga que llevar siempre consigo el lastre de su pasado, viviendo, irremediablemente, un presente perpetuamente atenazado por el mismo.

Hasta ahora, había sostenido que las premisas neurotécnicas de la memoria humana se concentraban en el hipocampo (en el caso de la memoria remota) y en la corteza prefrontal (en el caso de la memoria inmediata o próxima) y que los procesos humanos de memoria dependían de la transición de la segunda a la primera, sea por impacto o repetición ${ }^{44}$. Con carácter añadido, resulta interesante el análisis y la tipología que nos presentan Schock y Knaevelsrud sobre la memoria y su correlación con el trauma (o la retraumatización) en función del sistema de memoria fisiológico ${ }^{45}$. Llegados a este punto, podemos sugerir un auténtico paralelismo inverso entre la memoria humana y lo que algunos autores han llamado la memoria colectiva

43 Pues el olvido, en palabras de Khalil Gibran, es una forma de libertad.

44 Así lo he defendido, basándome en las teorías de Preston y Eichenbaum, en M. MARTÍNEZ LÓPEZ-SÁEZ, M.: “Nuevos perfiles del derecho al olvido... cit., p. 233. Vid., por tanto, A.R. PRESTON y H. EICHENBAUM, "Interplay of hippocampus and prefrontal cortex in memory", Current Biology, vol. 23, núm. 15, 2013, pp. 764-773.

45 K. SCHOCK y C. KNAEVELSRUD, "Retraumatization: The Vicious Circle of Intrusive Memory" en M. LINDEN y K. RUTKOWSKI (eds.), Hurting Memories and Beneficial Forgetting Posttraumatic Stress Disorders, Biographical Developments, and Social Conflicts, Elsevier, London, 2013, pp. 61-62. Ellos hablan del hipocampo y la amígdala, dividiendo la conocida memoria a largo plazo en dos categorías: la memoria explícita y la memoria implícita. En el caso de la primera, a la que también denominan "memoria declarativa" (o "fría" siguiendo su metáfora térmica), declaran que los recuerdos, por un lado, pueden recuperarse conscientemente, pues el contenido del evento en cuestión está disponible y accesible fácilmente, y, por otro lado, el contenido recordado incluye no solo la información básica sino también la circunstancial (elementos espaciales, temporales, otras personas presentes, etc.). En contraposición, en el caso de la segunda, a la que también llama "memoria no declarativa" (o "caliente" siguiendo la supracitada comparación), los recuerdos son imprevisibles e inconscientes, pues estos se almacenan únicamente en función de la percepción sensorial y emocional del evento en cuestión, o, como lo abordan ellos "en el marco de una red asociativa" que solo requiere "la activación de un único elemento" para habilitar el acceso al recuerdo. 
o social ${ }^{46}$ en el mundo virtual, algunos otros la memoria "transaccional" ${ }^{47} \mathrm{y}$ otros simplemente la memoria digital ${ }^{48}$. Con independencia del término que se utilice, el problema que surge parece claro: cuando las relaciones humanas son confiadas, y la memoria humana está relegada, a infinitos bancos de datos y a una amalgama ilimitada de herramientas y sistemas, que permiten el almacenamiento por tiempo indefinido y la accesibilidad inmediata, con independencia del contexto espacio-temporal, perdemos la capacidad de controlar nuestra propia identidad e existencia. Es incontestable que las personas dejamos una huella digital ${ }^{49}$, venga esta dado por las exigencias de vivir en un sistema democrático, y por tanto, burocrático, o venga de las consecuencias naturales de interactuar en la Red, haciendo la expresión quod nos est in Google, non est in mundo ${ }^{50}$ tan cierta como reveladora y desconcertante. Todo lo que se le ha confiado a la Red, sea de manera consciente o no, sea de manera consentida o no, queda barnizado en un espacio sin fronteras y que

46 E. ESPOSITO, La memoria sociale. Mezzi per comunicare e modi di dimenticare, Laterza, Roma, 2001; y más recientemente, A. SALARELLI, “Diritto all'oblio e archivi online dei quotidiani: alcune considerazioni sulla memoria sociale ai nostri tempi", JLIS: Italian Journal of Library, Archives, and Information Science, vol. 5, núm. 1, 2014, p. 1; y R. GARCÍA-GAVILANES, A. MOLLGAARD, M. TSVETKOVA y T. YASSERI, "The memory remains: Understanding collective memory in the digital age", Science Advances, vol. 3, núm. 4, 2017, pp. 1-7.

47 D.M. WEGNER, "Transactive memory: a contemporary analysis of the group mind", en B. MULLEN y G.R. GOETHALS (eds.), Theories of group behaviour, Springer Nature, Basel, 1987, pp. 185208, y más adelante en A. F. WARD, "Supernormal: How the Internet is changing our memories and our minds", Psychological Inquiry, vol. 24, núm. 4, 2013, pp. 341-342; y J. FIRTH, J. TOROUS, B. STUBBS, J.A. FIRTH, G.Z. STEINER, L. SMITH, M. ALVAREZJIMENEZ, J. GLEESON, D. VANCAMPFORT, C.J. ARMITAGE y J.SARRIS, “The 'online brain': how the Internet may be changing our cognition", World Psychiatry, vol. 18, 2019, p. 122. Estos dos últimos, de hecho, hablan de las consecuencias nefastas que produce la memoria ilimitada de Internet para las funciones cognitivas: desde la reducción de la capacidad de atención y la memoria semántica hasta problemas socio-psicológicos de la ubicuidad que caracteriza a la red de redes.

48 Se trata, pues, de una memoria que no sólo trasciende los límites de la memoria humana, diseñada ingeniosamente con la capacidad de olvidar, sino que, además, almacena toda la información generada por los usuarios de forma manual o directa y toda aquella información generada por su comportamiento. Vid. M. MARTÍNEZ LÓPEZ-SÁEZ, “Nuevos perfiles del derecho al olvido... cit., p. 233.

49 E. DELGADO VALLE, “Derecho al recuerdo en Internet”, en J. VALERO TORRIJOS (coord.): La Protección de los Datos Personales en Internet ante la Innovación Tecnológica, ThomsonReuters Aranzadi, Navarra, 2013, p. 436: "Incluso la más retraída y menos proactiva de las personas deja, en la actualidad, un rastro de su existencia".

50 R. MARTÍNEZ MARTÍNEZ, “¿Quién debería olvidarnos en Internet?” Revista Actualidad Jurídica Aranzadi, núm. 864, 2013, pp. 1-3.

DERECHOS Y LIBERTADES

ISSN: 1133-0937

Número 46, Época II, enero 2022, pp. 177-211

DOI: https://doi.org/10.20318/dyl.2022.6518 
no conoce límites. El personaje de Borges, Funes el Memorioso, y su sueño como depurador de recuerdos, terminó encontrando un competidor feroz ${ }^{51}$ y un digno oponente. En efecto, si algo ha traído Google y sus competidores análogos ha sido la memoria en superlativo ${ }^{52}$. En otras palabras, Google y compañía reflejan el epítome de la memoria, trayéndola a primera línea de batalla; una batalla existente desde hace décadas entre el derecho cuasi colectivo al acceso ilimitado al conocimiento e ideas frente a la intimidad y autodeterminación informativa del individuo.

En efecto, la infalibilidad de la memoria absoluta de Internet se contradice con los límites de la memoria humana, lo que sin duda alguna significa que las huellas que dejamos en el mundo digital, permanecen y nos siguen, como una sombra ${ }^{53}$, dondequiera que vayamos. La memoria digital eterniza el elemento del tiempo, tan arraigado en nuestra propia existencia, pues impide que las personas se separen de su pasado, lo que, a su vez, puede evitar un crecimiento y desarrollo humano saludable. Como también ha afirmado Szekely, en comparación con la memoria digital, la memoria humana es imperfecta ${ }^{54}$, porque distorsiona, omite y selecciona aleatoriamente, o no, qué información lleva a extremos desorbitados del recuerdo y qué información envía a la fuente del olvido y la insignificancia. Si bien no discrepamos de su caracterización de la memoria humana, sí lo hacemos de su consideración contrastiva. Recordemos que la memoria digital que supone la Red y aquellas herramientas de localización instantánea de la información que esa reserva inabarcable encuentra, como los motores de búsqueda, es igualmente imperfecta, pues también distorsiona, selecciona y clasifica la información -no siempre por el mismo criterio objetivo- y siempre la presenta fuera de su contexto temporal original, extrayéndola de los confines más profundos

51 J.L. BORGES, "Funes el Memorioso", en Ficciones. El Aleph. El Informe Brodie (1942), Destino, Barcelona, 2009, pp. 51-55.

52 En efecto, la memoria ahora, en palabras de Osten: "[ha sido] experta en el trato con asociaciones auto-generadas y clarividencias conexas, de repente se encuentra otra vez -y en cuanto usuaria habituada a capacidades de almacenaje - con conexiones formales técnicamente determinadas y dependiente de las 'máquinas de búsqueda' digital". Vid. M. OSTEN, La memoria robada. Los sistemas digitales...cit., p. 79.

53 A. GHEZZI, A. GUIMARES PEREIRA y L.VESNIC-ALUJEVIC, The ethics of memory in a digital age: interrogating the right to be forgotten, Palgrave Macmillan, Londres, 2014, p. 11.

54 I. SZEKELY, "The Right to Forget, the Right to be Forgotten Personal Reflections on the Fate of Personal Data in the Information Society, en S. GUTWIRTH, R. LEENES, P. DE HERT, e Y. POULLET (eds.), European Data Protection: In Good Health?, Springer, Dordrecht, 2012, p. 355. 
de la tierra del ciberespacio. Es precisamente "la amplia gama de información, a veces anárquica, a veces perfectamente ordenada, pero siempre descontextualizada, en la Red" lo que hace de la ciudad virtual que es la Red de Internet, los mandatarios que la controlan y todos los súbditos que conviven en ella "lo que la hace tan potencialmente perjudicial" 55 .

Como ya han expuesto los grandes especialistas en la materia, históricamente, el olvido era la regla y la memoria la excepción, pero hoy en día la transformación tecno-digital ha invertido los roles, elevando al recuerdo no solo como regla por defecto y diseño ${ }^{56}$ sino como mandamiento absoluto de la deidad en la que se ha convertido la omnipresente, omnisciente y omnipotente Red que dispone y conoce todo. Y, de hecho, incluso siguiendo las categorías propuestas por Schock y Knaevelsrud, esto es incluso más problemático, pues la propia naturaleza de la Red, y su versión mejorada gracias a los operadores fieles que residen en ella, hacen que esta sea simultáneamente memoria explícita e implícita, seleccionando lo más perjudicial de ambas: por un lado, es capaz de recuperar todo tipo de información de manera fácil e instantánea y lo puede hacer con la activación de un único elemento -el nombre de la persona-. Esta situación se agrava en tanto en cuanto esta información se presenta vestida de engaño, de manera estructurada y actual, pues la despoja de su contexto y la encabeza como lo más relevante del presente con independencia del trascurso del tiempo.

\subsection{El perjuicio de la memoria digital para la vida real: influencias nietzscheanas, benthianas y orwellianas}

Si bien no compartimos las perspectivas utilitaristas, por considerar la utilidad contraria a la dignidad e individualidad humana ${ }^{57}$, hay argumentos de Nietzsche sobre el "perjuicio de la historia para la vida" 58 , y, por exten-

55 M. MARTÍNEZ LÓPEZ-SÁEZ, “Los nuevos límites al derecho al olvido en el sistema jurídico de la Unión Europea: la difícil conciliación entre las libertades económicas y la protección de datos personales", Estudios de Deusto, vol. 65, núm. 2, 2017, p. 171.

56 En un principio V. MAYER-SCHÖNBERGER, Delete: The Virtue of Forgetting....cit., pp. 2, 44 y 196; y más reciente, A. RALLO LOMBARTE, El derecho al olvido en Internet ... cit., p. 17.

57 La dignidad humana, para los que todavía defendemos las premisas del iusnaturalismo, tiene un valor intrínseco, no como medio o instrumento que se utiliza para un fin social más amplio o más importante, ni para maximizar la utilidad. Por sí misma, la persona tiene un valor intrínseco que merece ser respetado. Y por tanto, es un error pensar en la justicia o en el derecho como la suma de preferencias o de balances de coste-beneficio.

58 F. NIETZSCHE, Sobre la utilidad y el perjuicio de la historia para la vida: II Intempestiva (trad. G.CANO), Biblioteca Nueva, Madrid, 1999.

DERECHOS Y LIBERTADES

ISSN: 1133-0937

Número 46, Época II, enero 2022, pp. 177-211

DOI: https://doi.org/10.20318/dyl.2022.6518 
sión de la memoria, que resultan interesantes en el contexto del derecho al olvido, pues, aunque proporciona argumentos propios de las críticas a la negación histórica, también se sostiene sobre posturas propias de la negación de la filosofía de la historia ${ }^{59}$. Así, especula sobre el deseo innato, e incluso necesario, de olvidar, para no encerrarse en un horizonte limitado, sin que ello implique descartar reflexiones y críticas de qué es exactamente lo que se debe, o no, olvidar, para no producir la ignorancia de las injusticias. Así, por un lado, destaca la cruel y oscura perspectiva que se adopta cuando se suspende temporalmente el olvido ${ }^{60}$, examinando el pasado, generalmente, despreciando cualquier tipo de justificación o clemencia, perspectiva que se considera peligrosa para la vida misma, en tanto en cuanto se juzga y se aniquila el pasado, desmoronando y degenerando, a su vez, el presente y el futuro $^{61}$. Por otro, recuerda que la verdad antagónica de que todos (como país, como sociedad, como generación $-y$, por supuesto, como individuos-) somos resultado de nuestro pasado, y que si bien parece imposible liberarse de sus cadenas o errores, ello no impide la lucha innata por una nueva versión renovada y mejorada de uno mismo, en contraposición con la rémora que puede pervivir desde nuestro pasado, una versión o naturaleza que, a base de hábitos, conduce inexorablemente a la transformación posterior de la naturaleza en la principal y hace que la anterior desaparezca ${ }^{62}$.

Nietzsche duda de esta posibilidad, pues considera difícil encontrar un equilibrio sano entre la negación del pasado y el triunfo de su superación ${ }^{63}$. No obstante, admite que soportar la carga cada vez más aplastante del pasado, que resulta abrumadora y paralizante, supone un obstáculo para la marcha hacia delante y el desarrollo de la persona ${ }^{64}$. Habla del exceso de la historia como amenaza constante para la vida; habla de la "sobresaturación" histórica del pasado como fuerza debilitante de la personalidad, como obstáculo para la madurez y píldora peligrosa del cinismo y egoísmo ${ }^{65}$. Así, el olvido de las cadenas del pasado es conditio sine qua non de la máxima de la felicidad ${ }^{66}$. Muchos otros estudiosos nos han advertido sobre la oposición y la dualidad olvido/memoria.

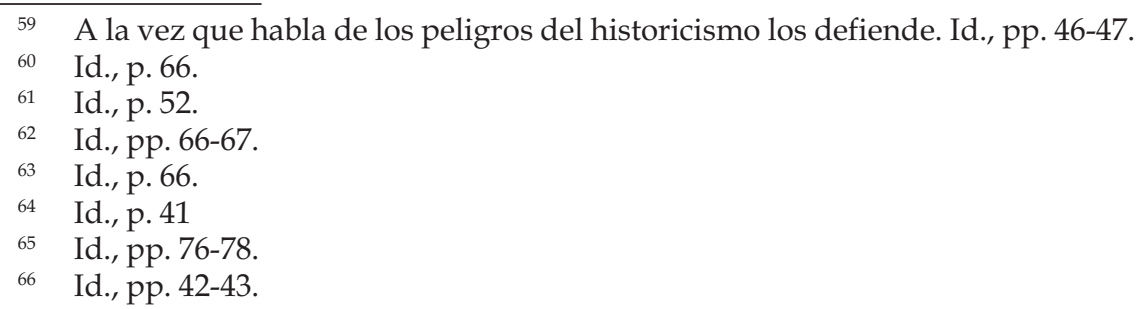


Resulta difícilmente cuestionable que la historia de la humanidad se ha movido y sigue moviéndose "en un vaivén ininterrumpido entre memoria y olvido" ${ }^{67}, \mathrm{y}$ por ende, también se mueven así las reflexiones acerca de los mismos.

Sin embargo, con el auge incesante de la "memoria de acero" ${ }^{8}$ de Internet, y su perfeccionamiento a causa de la labor de los motores de búsqueda, el vaivén se desequilibra por completo, para dar paso a una suerte de limbo en el bando de las fuerzas reminiscentes. El híbrido resultante de la simbiosis entre la versión 2.0 de la Biblioteca de Alejandría, la versión 2.0 del Panóptico benthiano y la versión 2.0 de la Galaxia de Gutenberg no supone únicamente una "crisis de valores" en el acceso a información de "calidad" 69, sino la herramienta clave para sistemas opresivos de los que ya nos advirtieron, entre otros, Orwell, Zamyatin y Huxley ${ }^{70}$. Sin entrar en cuestiones ampliamente estudiadas sobre las nuevas facetas de la vigilancia electrónica, tanto pública como privada (surveillance), sí que cabe, al menos, citar al nuevo fenómeno de la dataveillence en la era post-Snowden ${ }^{71}$ y la transformación del Panóptico al Períptico, en tanto ya ni sabemos quién nos vigila, ni cómo, ni para qué ${ }^{72}$. En tal sentido, la transformación digital, en general, y la Red, en particular, se han convertido en el 'Gran Hermano' que nos vigila, manipula nuestra libertad y, lo que es peor, están (y nos ponen) al servicio de más de un amo (el Estadonación en su sentido clásico o desde el prisma de los nuevos "Estados" digitales como es Facebook Nation ${ }^{73}$ ).

\footnotetext{
67 H. BAUZÁ, Sortilegios de la memoria y el olvido, Akal, Buenos Aires, 2015, p. 19.

68 B.J. KOOPS, "Forgetting Footprints, Shunning Shadows. A Critical Analysis of the ‘Right To Be Forgotten' in Big Data Practice”, SCRIPTed, vol. 8, núm. 3, 2011, p. 2.

69 "una crisis de valores al haber confundido cantidad con calidad; así, por ejemplo, nos presentan la falacia de hacernos creer que algo es bueno [o cierto] en tanto ha sido mencionado muchas veces" según H. BAUZÁ, Sortilegios de la memoria y el olvido... cit., p. 118.

70 Aldous Huxley en Un Mundo Feliz y George Orwell en 1984 han puesto precisamente el acento sobre el problema del trans-humanismo y la "supra-revolución" tecnológica; problemática que se ha hecho realidad y cuya reflexión sigue siendo de lo más acertada a día de hoy.

71 Una suerte de recogida y agregación panóptica en la que los datos reunidos a través de las prácticas de vigilancia del ciudadano ordinario da paso a mecanismos de vigilancia del Estado, a través de las corporaciones que poseen esos datos. Vid., V. BAKIR,"Veillant panoptic assemblage. Mutual watching and resistance to mass surveillance after Snowden" Media and Communication, vol. 3, núm. 3, 2015, pp. 12-25; y, más recientemente, las referencias que hace Sancho López a la "normalización social de la cultura de la vigilancia" y el concepto de "dataveillence", en M. SANCHO LÓPEZ, El derecho al olvido en el big data: nuevos retos para la protección de la privacidad, Tesis Doctoral, Universidad de Valencia, 2018, pp. 39-47.

72 I. SZEKELY, “The Right to Forget, the Right to be Forgotten...", cit., p. 352.

73 N. LEE, Facebook Nation: Total Information Awareness, Springer, New York, 2014.
} 
Tomamos prestadas precisamente las palabras de Orwell "Quien controla el pasado controla el futuro. Quien controla el presente controla el pasado". Si bien esta sombría realidad se presenta sumamente problemática en el caso de que el control se sitúe sobre la cima en la cadena del poder, en un sistema político y ordenamiento jurídico, en el supuesto de que fuera el propio individuo el que tuviera este poder de control, se marcaría una radical diferencia. Inspirados en Rodríguez de las Heras ${ }^{74}$, no podemos sino compartir la pregunta con la que da comienzo a su presentación: antes del perfeccionamiento de la era 4.0 había que preguntarse si el destino o lo que nos depara el futuro, estaba escrito; ahora, la pregunta es justo la contraria, ¿determina lo que está escrito (en la Red) lo que nos depara el futuro? La respuesta, a nuestro pesar, es en clave afirmativa. Ante estos escenarios y frente a este horizonte desconcertante, cabe aludir a un retocado ars oblivionalis ${ }^{75}$ tanto como respuesta a los retos que plantea la memoria absoluta e indulgente de la transformación digital, en general, y de la Red, en particular, como mecanismo natural adaptado a las exigencias actuales. De ahí que el derecho al olvido se haya denominado un derecho a la "muerte digital" 76 .

El recuerdo y el olvido son elementos inseparables de la condición humana y del cerebro humano, ingeniosamente diseñados, en su creación y evolución, con esa capacidad de destruir lo superfluo o lo dañino, de lo que se hace eco la expresión que acuña Bauzá y que adaptamos "bienaventurados los desmemoriados" 77 porque de ellos es el reino de la paz y la salud emocional. Recordamos y olvidamos selectiva e inconscientemente; a veces somos nosotros mismos los que anhelamos y deseamos olvidar, a veces es el propio cerebro el que, como mecanismo de autodefensa o por economía organizativa, decide descartar lo irrelevante o imponernos cierto olvido, todo ello con el fin último de no impedir avanzar y disfrutar del presente y el futuro. Las reflexiones de Osten al respecto, y su paralelismo con el paradigma digital actual son de obligada referencia ${ }^{78}$.

74 T. RODRÍGUEZ DE LAS HERAS, “El derecho al olvido”, TEDxUPValència, 2016.

75 H. WEINRICK, Lethe: the Art and Critique of Forgetting (trad. S. RENDALL), Cornell University Press, Ithaca, 2004, pp. 11-12.

76 V. ESCANDÓN PRADA, El olvido en los tiempos de las fake news, Tesis Doctoral, Universidad de Oviedo, Oviedo, 2019, p. 68.

77 H. BAUZÁ, Sortilegios de la memoria y el olvido... cit., p. 51.

78 M. OSTEN, La memoria robada. Los sistemas digitales.... cit., p. 105: "recuerdo y olvido ¿son sólo algoritmos de las funciones del cerebro? ¿Cambia el concepto de la memoria, lenta pero seguramente, del plano individual o colectivo al plano biológico? ¿Es la fragilidad de la memoria en 
La naturaleza absoluta y perpetua de Internet, en contraposición con la humana, permitiendo que las huellas que dejamos en el mundo digital, permanezcan y nos sigan, como sombras digitales de manera temporalmente irrestricta, rinde homenaje a las reflexiones del poeta latino Virgilio sed fugit interea, fugit irreparabile tempus, o en el caso de la Red, más bien tempus fugit non autem memoria digitalis. La puesta a disposición atemporal de la información personal que permite la Red ha dado lugar a un verdadero efecto "eternizador" 79 o "de contemporaneidad" 80 entre lo hecho, dicho (o lo que han hecho o dicho sobre nosotros) en el pasado y el presente, difuminando la línea divisoria entre ambos. Con semejante instrumento, los recuerdos, los buenos, los malos, los feos ${ }^{81}$, hasta los no consentidos, quedan grabados en la Red, devenida una suerte de bomba (y subsiguiente lápida) personal o profesional de relojería. Y así, el derecho al olvido, es, a fin de cuentas, poder decidir quiénes somos, poder controlar lo que está escrito sobre nosotros. Si no pudiéramos controlar lo que está escrito en la Red, ¿podríamos controlar realmente nuestro destino?

\section{LA POSTURA IUSFUNDAMENTAL DEL DERECHO AL OLVIDO DIGITAL}

Como apuntan Pagallo y Durante, la memoria y el olvido "cooperan en la construcción de la identidad personal" y son las "dos caras de una misma moneda" ${ }^{82}$. En tal sentido, como hemos podido observar, mantener sine die cierta información de carácter personal tiene efectos gravemente perjudiciales para

definitiva deudora de la evolución? Así como esta nos regala el recuerdo ¿nos regala también al parecer con el beso del olvido? Con un olvido que nosotros mismos en todo caso fomentamos mientras tanto con vehemencia individual, colectiva y digitalmente. Quizá se podría definir en este sentido la posmodernidad como una sociedad de riesgo anamnético, cuyo saber técnico-informativo entiende al hombre cada vez más como un agregado neuroquímico en tránsito hacia la inteligencia y existencia artificial digitalmente dirigidas".

79 C. DE TERWANGNE, The Right to be Forgotten and the Informational Autonomy in the Digital Environment, en A. GHEZZI, A. GUIMARES PEREIRA y L.VESNIC-ALUJEVIC, The ethics of memory in a digital age: interrogating the right to be forgotten, Palgrave Macmillan, Londres, 2014, p. 84.

80 J.C. SUÁREZ VILLEGAS, “El derecho al olvido... cit., p. 40.

81 M. MARTÍNEZ LÓPEZ-SÁEZ, "Nuevos perfiles del derecho al olvido... cit., p. 234.

82 U. PAGALLO y M. DURANTE, "Legal Memories and the Right to be Forgotten" en L. FLORIDI (ed.) Protection of Information and the Right to Privacy - A new Equilibrium, Springer, Basel, 2014, p. 19.

DERECHOS Y LIBERTADES

ISSN: 1133-0937

Número 46, Época II, enero 2022, pp. 177-211

DOI: https://doi.org/10.20318/dyl.2022.6518 
la dignidad y el libre desarrollo de la persona y esa construcción de su identidad, llevándole, potencialmente, a ningún otro puerto que al de una suerte de muerte civil -en ocasiones incluso laboral y mercantil-, imposibilitando la autorrealización de cualquier faceta vital. Es precisamente a tal efecto que se han generado no pocas preocupaciones sobre el impacto de la memoria extraordinaria e infalible de las NTIC y en particular de la Red, que lo hace todo más accesible, sobre el libre desarrollo y dignidad de las personas. De esta, precisamente, ha surgido la paradójica necesidad de "acordarse de olvidar" 83 , pues el olvido, como veremos, tiene más virtudes que vicios en el contexto digital.

Ante nuestra insistencia en el respeto de la dignidad humana, en tanto que "referente metafísico" ${ }^{84}$, y la protección de los derechos fundamentales (especialmente, por lo que se refiere a este trabajo, los que denominamos digitales), consideramos importante efectuar unas aclaraciones conceptuales y reflexiones preliminares adicionales. En primer término, cabe resaltar que no compartimos la clasificación generacional de los derechos humanos ${ }^{85}$, pues, en los tiempos actuales, y desde los orígenes del Derecho, la elección de las palabras importa, y por ende, preferimos posicionarnos en la necesidad de enfatizar su universalidad, indivisibilidad, interdependencia y su fundamento compartido en la dignidad humana ${ }^{86}$. Así, entendemos la dignidad humana como "referente humano para la construcción de la universalidad real en derechos, libertades y exigencias de justicia" ${ }^{87}$. En segundo término, sí que resulta relevante su materialización como categorías históricas o a tra-

83 V. MAYER-SCHÖNBERGER, “Remembering (to) Delete: Forgetting Beyond Informational Privacy" en F. THOUVENIN (ed.), Remembering and Forgetting in the Digital Age (Law, Governance and Technology Series), Springer, Cham, 2018, p. 123.

84 J.M. GUTIÉRREZ DÍAZ, Proyección práctica de la dignidad humana, Fundación Emmanuel Mounier, Madrid, 2014, p. 11.

85 Cuyo máximo exponente fue en su día K. VASAK, “Human Rights: A Thirty-Year Struggle: the Sustained Efforts to give Force of law to the Universal Declaration of Human Rights", UNESCO Courier 30:11, United Nations Educational, Scientific, and Cultural Organization, Paris, 1977; y cuya clasificación también se encuentra en numerosos trabajos de excelencia académica, examinando los derechos en esta clave: véase, con carácter más reciente J. BUSTAMANTE DONAS, “La cuarta generación de derechos humanos en las redes digitales", TELOS, 2010, pp. 1-10.

86 Recordemos la Declaración y el Programa de Acción de Viena adoptada por la Conferencia Mundial de Derechos Humanos el 25 de junio de 1993. Versión en español disponible en: https://www.ohchr.org/Documents/Events/OHCHR20/VDPA_booklet_Spanish.pdf

87 J.M. GUTIÉRREZ DIAZ, Proyección práctica de la dignidad... cit., p. 13.

ISSN: 1133-0937

DOI: https://doi.org/10.20318/dyl.2022.6518
DERECHOS Y LIBERTADES

Número 46, Época II, enero 2022, pp. 177-211 
vés de "contextos temporalmente determinados" 88 . Como magistralmente apunta Salvioli: si bien las clasificaciones teóricas de los derechos pretenden agruparlos con el fin de incidir en su surgimiento histórico, su reconocimiento, grado de exigibilidad o de las garantías jurídicas al alcance de sus titulares, esto no debe desvirtuarles de su indivisibilidad, de su condición 'fundamental' (pues todos, en tanto en cuanto derivan de la dignidad humana como categoría universal, lo son) ${ }^{89}$.

En tal sentido, a diferencia de las mal llamadas primera, segunda y tercera generación de los derechos humanos, como productos de teorías y movimientos de diversa índole, la archiconocida 'cuarta generación' de derechos es el resultado directo de la experiencia humana y su relación con el entorno tecno-digital, y específicamente en el contexto del ciberespacio, la "expansión del concepto de ciudadanía digital" ${ }^{90}$ y la "apropiación social de las nuevas tecnologías" ${ }^{91}$. A pesar de cierta crítica ${ }^{92}$, estos derechos se han llamado, y hemos venido llamando, 'nuevos' derechos o derechos 'digitales' o 'emergentes', entre los que indudablemente se circunscriben el derecho a la protección de datos y el derecho al olvido. Con todo lo anterior en mente, si bien es verdaderamente útil, en el contexto docente, y resulta sumamente atractivo en la difusión y transferencia del conocimiento, catalogar y denominar a los derechos en función de su proceso de reconocimiento histórico, no resulta del todo conveniente ${ }^{93}$.

88 A.E. PÉREZ LUÑO, "Las generaciones de derechos fundamentales", Revista del Centro de Estudios Constitucionales, núm. 10, 1991, p. 205.

89 F.O. SALVIOLI, Introducción a los Derechos Humanos: concepto, fundamentos, características, obligaciones del Estado y criterios de interpretación jurídica, Instituto Interamericano de Responsabilidad Social y Derechos Humanos, México, 2019, pp. 132-133.

90 E. DELGADO VALLE, “Derecho al recuerdo en Internet... “,cit., pp. 418-421.

91 E. DELGADO VALLE, “Derecho al recuerdo en Internet...”, cit., p. 421.

92 Subrayar, a modo anecdótico, que si bien hay un acuerdo considerable entre la doctrina académica, autores como Pérez Luño han considerado estos derechos particularmente afectados por las NTIC como parte de la tercera generación, al no considerar que otras denominaciones contribuyen a mayores malentendidos y confusiones. Vid., en tal sentido, A.E. PÉREZ LUÑO, Los Derechos Humanos en la sociedad tecnológica, Editorial Universitas, Madrid, 2012, pp. 17-25.

93 M. MARTÍNEZ LÓPEZ-SÁEZ, “La Carta Social Europea y los derechos sociales emergentes: una aproximación al derecho de acceso a la información ambiental", Lex social: revista de los derechos sociales, vol. 9, núm. 1, 2019, p. 175: "conviene evitar la paradoja proveniente de tal encasillamiento, principalmente la conversión de prioridades cronológicas en prioridades axiológicas [...] semejante jerarquización, vinculada a dicha idea restrictiva de fundamentalidad, no es objeto de unanimidad, máxime cuando se tienen presentes los estándares internacionales sobre derechos hu-

DERECHOS Y LIBERTADES

ISSN: 1133-0937

Número 46, Época II, enero 2022, pp. 177-211

DOI: https://doi.org/10.20318/dyl.2022.6518 
La clasificación de los derechos debe tener como único objetivo un mayor entendimiento de su origen y evolución, y no provocar "jerarquías incompatibles con las características de indivisibilidad e interdependencia" ${ }^{94}$. Apoyándonos en las declaraciones de Leturia Infante, el derecho al olvido debe ser analizado desde la lógica de los derechos fundamentales ${ }^{95}$, y, por supuesto, desde su proyección de la dignidad humana. No nos cabe duda de que los derechos emergentes, como es el derecho a la protección de datos y su faceta en el derecho al olvido, dimanan directamente de la dignidad humana como valor, principio angular y fundamento del ordenamiento jurídico europeo. La dignidad, según su acepción kantiana, hace referencia a un valor inherente al ser humano por el simple hecho de serlo, en cuanto ser racional, dotado de libertad; es decir, la dignidad se proyecta como cualidad consustancial al ser humano. De un análisis conjunto del constitucionalismo europeo, del cual se puede vislumbrar el carácter inseparable de la relación dignidad/derechos, concluimos que la proyección sobre los derechos humanos se fundamenta en la dignidad de la persona, la cual no solo constituye el punto de arranque del reconocimiento de los demás derechos, sino que, además, es la esencia que permanece inalterada, con independencia de la situación o estado de la persona, constituyendo un "mínimum invulnerable", que impide limitaciones en el disfrute de estos, si conllevan el "menosprecio para la estima que, en cuanto ser humano, merece la persona" ${ }^{96}$.

Aunque la noción de la dignidad humana no la encontremos expresamente reconocida en los instrumentos más importantes de la UE, hasta la reforma del Tratado de Lisboa que revisa los tratados constitutivos e incorpora la CDFUE como parte del Derecho originario, otorgándole una naturaleza jurídicamente vinculante, se puede decir con total y absoluta certeza que la dignidad humana y su protección ha sido un valor latente en la Europa de la

manos (y la idea de indivisibilidad)". Conviene traer a colación, en tal sentido, las contribuciones de J. MORA GALIANA, "Preferencias axiológicas y valores jurídicos. Para una deontología profesional”, Cuadernos Electrónicos de Filosofía del Derecho, 2009, pp. 166-179; y J.L. MONEREO PÉREZ, "El principio de indivisibilidad e interdependencia en el sistema jurídico internacional multinivel de garantía de los derechos fundamentales", Revista derecho del trabajo, núm. 15, 2017, pp. 21-68.

94 F.O. SALVIOLI, Introducción a los Derechos Humanos... cit., p. 138.

95 F. J. LETURIA INFANTE, “Fundamentos jurídicos del derecho al olvido, ¿un nuevo derecho de origen europeo o una respuesta típica ante colisiones entre ciertos fundamentos?", Revista Chilena de Derecho, vol. 43, núm. 1, 2016, pp. 91-113.

96 Así de elocuentemente lo ha puesto nuestro propio Tribunal Constitucional. Vid. STC 120/1990, de 27 de junio (FJ 4). 
segunda posguerra. La CDFUE, como instrumento de tutela de los derechos y libertades, precisamente en su primer Título lleva por rúbrica "Dignidad", sirviendo de pórtico a los sucesivos Títulos. Encontramos la misma lógica del mínimo invulnerable en el art. 1 CDFUE ("La dignidad humana es inviolable. Será respetada y protegida") y en las explicaciones elaboradas bajo la responsabilidad del Praesidium de la Convención que redactó la CDFUE: "la dignidad de la persona humana no solo es en sí un derecho fundamental, sino que constituye la base misma de los derechos fundamentales"97. Así, la inmunidad de la dignidad a sufrir injerencias, en el seno de la UE, se manifiesta como parte del contenido esencial de cada derecho; no pudiendo atentar contra ella, incluso en caso de limitación de los derechos reconocidos en la misma ${ }^{98}$. En otras palabras, la CDFUE detalla el sentido inseparable de la noción de dignidad que se pretende dar a la idea actual de Europa, por lo que lo reitera como límite y concepto informador de toda la actuación de la UE, y, en definitiva, como base axiológica absoluta.

Este complejo concepto ha sido completado como garantía negativa (derecho a no sufrir injerencias) y positiva (autodisponibilidad y autodeterminación de la persona) o lo que se ha resumido como el pleno desarrollo de la personalidad $^{99}$. La dignidad de la persona es el fundamento de los derechos humanos, siendo estos, por tanto, concreciones de aquella para el desarrollo integral de la persona. La dignidad, como fundamento de los derechos humanos y estos como concreciones de esta para el desarrollo integral de la persona. La dignidad humana, como mínimo (y máximo) denominador común del enfoque basado en los derechos humanos, se ve particularmente reflejada en los principales instrumentos jurídicos internacionales, europeos así como nacionales ${ }^{100}$.Volviendo a la teoría kantiana de la dignidad, su concepción como

97 Explicaciones sobre la Carta de los Derechos Fundamentales de 14 de diciembre de 2007. Disponible en: https://eur-lex.europa.eu/legal-content/ES/TXT/PDF/?uri= CELEX:32007X1214(01)Efrom $=$ EN

98 En otras palabras: "la Carta describe el sentido inseparable de la noción de dignidad que se pretende dar a la idea actual de Europa, se reitera como límite y concepto informador de toda la actuación de la UE o, en otras palabras, como base axiológica absoluta". Vid. M. MARTÍNEZ LÓPEZ-SÁEZ, Una revisión del derecho fundamental a la protección... op.cit., p. 46.

99 A.E. PÉREZ LUÑO, Derechos Humanos: Estado de Derecho y Constitución, Tecnos, Madrid, 2010, p. 324.

100 Para la evolución normativa y universalización de la noción de dignidad humana vid. M. MARTÍNEZ LÓPEZ-SÁEZ, M.: Una revisión del derecho fundamental a la protección de datos de carácter personal. un reto en clave de diálogo judicial y constitucionalismo multinivel en la Unión Europea, Tirant lo Blanch, Valencia, 2018, pp. 44-48. 
valor fundamental de las nociones de persona hace que igualmente englobe una dimensión moral de la personalidad, fundamentada en la propia libertad y autonomía individual, encarnándose a su vez, como principio legitimador de los llamados derechos de la personalidad. En semejante línea se ha evocado que los derechos fundamentales (o si se prefiere, humanos) son "la expresión singular de la dignidad humana", y así, su reconocimiento "como fundamento para los derechos humanos hace posible su dignificación" ${ }^{101}$.

\section{CONSIDERACIONES FINALES PARA QUE LA DIGNIDAD NO CAIGA EN EL OLVIDO}

\subsection{La dignidad humana y el libre desarrollo de la personalidad como priora lógicas y ontológicas para la autodeterminación informativa}

En las coordenadas expuestas, nuestra aproximación jurídico-filosófica comporta inexorablemente que el núcleo axiológico de la dignidad no caiga en el olvido. En efecto, en tanto en cuanto es fundamento y valor superior que garantiza el derecho de toda persona a definir libremente su proyecto de vida, en la era digital actual, esto indudablemente se pone en entredicho por las NTIC. En el caso del derecho a la protección de datos, y su concreción en el derecho al olvido, no sólo encontramos la dignidad humana como fundamento, sino que estos, del mismo modo, se especifican en la autorrealización del individuo, en el desarrollo de su identidad y de su personalidad, evidentemente relacionados con la libertad. Recordemos, además, la importancia que se le atribuyó a la vida privada y la intimidad, como garantía para la libertad y "autodeterminación personal", y en última instancia como garantía de "una mejor calidad de vida" ${ }^{102}$. Estos derechos, si se configuran bajo el paraguas amparador de la dignidad humana y la libertad, inexorablemente requieren de cierta potestad de control, y esto resulta especialmente necesario en el contexto de la revolución y mutación de la informática: "la libertad

101 M. MARTÍNEZ LÓPEZ-SÁEZ, Una revisión del derecho fundamental a la protección... cit., p. 48.

102 M. CARRILLO, "Los ámbitos del derecho a la intimidad en la sociedad de la comunicación" en Cuadernos y Debates núm. 248: El derecho a la privacidad en un nuevo entorno tecnológico, Centro de Estudios Políticos y Constitucionales, Madrid, 2016, p. 15. 
informativa representa una nueva forma de desarrollo de la libertad personal" ${ }^{103}$. No obstante, es una verdad, a nuestro juicio evidente, que la potestad de control que debería brindar la libertad, se ve coartada y limitada por el empleo de técnicas informáticas, que comprometen o menoscaban gravemente su práctica, en particular aquellas relativas al tratamiento de datos de carácter personal, como potencial agresión a lo más inherente de la persona resultante "del uso torticero del tratamiento automatizado de datos personales"104, que lo recopila todo y no nos lo deja olvidar.

Por todo lo anterior, y sobre la base de que el principio de selectividad está bien arraigado en el concepto de la memoria humana, al igual que los algoritmos neurológicos, establecen, por diseño y por defecto, cierto grado de oscuridad o de selectividad en el acceso de determinados recuerdos, por el bien del sistema en su conjunto, los algoritmos de la Red y los de sus operadores deberán contemplar una versión de oscuridad o desenfoque digital; lo que nosotros hemos llamado, según el contexto y la situación particular de la persona, un derecho al olvido en tanto que derecho de supresión, o un derecho al olvido digital en tanto derecho a la re-contextualización digital que motu proprio no permite la Red. Sin profundizar en los riesgos y consecuencias de las NTIC, a pesar de sus numerosas ventajas, hay que considerar aquí que operan, de una parte, como arma destructiva que pone en riesgo la dignidad humana, $y$, de otra, como escudo insuficiente frente a las víctimas de la guerra que ella misma genera. Desde el punto de vista de la protección de las personas en situación de vulnerabilidad, actúa como factor agravante de las mismas y, si no proporciona garantías y mecanismos efectivos, puede llegar a ser factor menguante en la protección de los derechos fundamentales de determinados colectivos. Ante la nueva y compleja realidad socio-digital, surge el reto (y subsiguiente deber) del Derecho (y por qué no, además la Ética) de paliar semejantes afrentas a la persona. Ello implica no sólo la conveniencia de reforzar los clásicos derechos personalísimos del ser humano, sino también la necesidad de asegurar una verdadera y efectiva autodeterminación informativa como presupuesto necesario para garantizar la dignidad humana (siendo esta, a su vez, prius lógico y ontológico) a través del diseño y ejercicio de nuevos mecanismos de tutela.

103 V. FROSINI, Informática y Derecho (trad. J, Guerrero y M. Ayerra Redín), Temis, Bogotá, 1988, p. 23.

104 A. GARRIGA DOMÍNGUEZ, “La nueva Ley Orgánica 15/1999, de 13 de diciembre de Protección de Datos Personales ¿Un cambio de filosofía?", Anales de la Cátedra Francisco Suárez, núm. 34, 2000, p. 305.

DERECHOS Y LIBERTADES

ISSN: 1133-0937

Número 46, Época II, enero 2022, pp. 177-211

DOI: https://doi.org/10.20318/dyl.2022.6518 
La concreción de derechos "emergentes" o la redefinición de los derechos "clásicos" responde a un proceso de evolución de las necesidades humanas como respuesta a los cambios y revoluciones y, por ende, a las consiguientes y potenciales amenazas que estas pueden tener sobre la libertad y dignidad individual; en definitiva, los derechos fundamentales deben redefinirse para adaptarse a los requisitos siempre cambiantes de nuevos contextos y realidades, y ello debe hacerse inspirándose en los principios y valores que los guían, siendo el orden axiológico máximo la dignidad. La necesidad de efectuar una constante revisión y perfilamiento de derechos fundamentales viene dada, entre otras muchas razones, por el supracitado progreso socio-tecno-digital, como recurso para evitar la "indigencia" de la persona ${ }^{105}$. Debido a la revolución tecnológica y a la actual transformación digital, vivimos en un mundo acompañado de una constante e imparable creación, almacenamiento e intercambio masivo de información y datos, en muchas ocasiones de carácter personal, que construyen identidades y perfiles digitales de los que nos volvemos esclavos y no podemos escapar.

Si bien somos seres de carne y hueso, parte de nuestra existencia e identidad está en la Red, troceada, desordenada y desperdigada en bits y bytes, pero fácilmente recuperable y presentada en un formato estructurado (si bien fuera de su contexto) en cuestión de un solo clic. Ortega y Gasset (1914) decía "yo soy yo y mi circunstancia", y, hoy en día nuestra circunstancia se multiplican, pues no son sólo las que se desarrollan en el mundo real sino también las que se desarrollan en el mundo virtual; o lo que, con mayor síntesis decía Rodotà bajo el lema "somos nuestros datos"106. En efecto, no somos nosotros los que decidimos quiénes somos, para el mundo digital y exterior, somos quien la Red y los motores de búsqueda dicen que somos ${ }^{107}$. Parece que estemos destinados a vivir dos vidas, la real y la virtual, pero a pesar de ello, en los tiempos que corren, parece solo importar la segunda (la identidad digital primigenia): "al igual que Proteo, la Red Internet no sólo lo sabe todo, sino que nunca olvida nada que constara en ella alguna vez"108. Parece que, en una época en la que la verdad es todo aquello que existe (en la Red),

105 N. BOBBIO, El tiempo de los derechos (trad. R. De Asís Roig), Editorial Sistema, Madrid, 1991,p. 18.

106 S. RODOTÀ, El derecho a tener derechos (trad. J.M. Revuelta López), Trotta, Madrid, 2014,p. 360.

107 En el correspondiente póster de la I Jornada de Divulgación de Tesis Doctorales de la Universitat de València, celebrada el 18 de enero de 2019.

108 M. MARTÍNEZ LÓPEZ-SÁEZ, “Nuevos perfiles...”, cit., p. 260.

ISSN: 1133-0937

DOI: https://doi.org/10.20318/dyl.2022.6518
DERECHOS Y LIBERTADES

Número 46, Época II, enero 2022, pp. 177-211 
somos testigos de un nuevo tipo de dictadura: la dictadura de la verdad posmoderna. Parece, además, que ante esta nueva realidad, estamos destinados a quedar invadidos, sometidos y manipulados, en función de los datos que recogen y exponen sobre nosotros, incluso "de manera invisible", por "mecanismos ingeniosos y máquinas pensantes" 109 construidas y operadas bajo premisas legítimas pero con intenciones encubiertas y riesgos impredecibles. Así, al igual que con la protección de datos, volviendo a tomar prestadas las palabras del maestro Rodotà, el derecho al olvido, de la misma manera, tiene el objetivo de retornarle a la persona autonomía, libertad y dignidad.

Con el fin de proteger y garantizar de manera eficaz los derechos y libertades puestos en entredicho por algunos de los usos de las NTIC, se ha visto necesario asumir una tarea de especialización en el seno de la UE, adquiriendo, el derecho a la protección de datos, algunas de las premisas del derecho al olvido: autonomía e independencia, aunque sin abandonar del todo su fundamentación originaria, basada en la dignidad humana, $\mathrm{y}$, de manera especial, en los demás derechos personalísimos del ser humano. Esta especialización (o si se prefiere, "singularización" ${ }^{110}$ ) obedece a la necesidad de dar mejor respuesta y mayor protección a la persona ante las posibilidades impensables de la tecnociencia. Así, a nivel europeo, se ha apostado por una clara regulación distintiva a través del cisma del clásico marco jurídico. El derecho a la protección de datos se regula en el art. 8 CDFUE como derecho autónomo y difiere de otro derecho protegido por la misma, el derecho a la vida privada y a la intimidad (art. 7 CDFUE). Esta distinción, coincidimos con Rodotà, no es "de fachada" "111. Cabe resaltar que la 'constitucionalización', como derecho fundamental, de la protección de datos, como autodeterminación informativa, queda, además, reforzada y ampliada por la cobertura jurídica, bajo la justificación de proteger la dignidad de la persona frente a los riesgos que supone el tratamiento de los datos de carácter personal.

\subsection{El derecho al olvido y otras fórmulas tecno-jurídicas para no su- cumbir ante la indigencia de la persona en tiempos digitales}

No podemos sucumbir al pesimismo que ocasiona ver las consecuencias demoledoras de las NTIC para los derechos fundamentales: Rodotà habla

\footnotetext{
109 S. RODOTÀ, El derecho a tener derechos... cit., p. 289.

110 L. REBOLLO DELGADO, El derecho fundamental a la intimidad, Dykinson, Madrid, 2005, p. 102.

111 S. RODOTÀ, El derecho a tener derechos... cit., pp. 360-361.
} 
del desafío a la identidad, del empobrecimiento de la capacidad de decidir, de la inutilidad de suplicar mayor privacidad ${ }^{112}$. Pero la resistencia que él considera vana debe producirse. Rechazamos vehementemente que la respuesta a las injerencias de la memoria infalible de Red en los derechos personalísimos sea la abstinencia digital, la autocensura, la acogida con beneplácito de la idea de que quien no tiene nada que ocultar no tiene nada que temer, la resignación a tener que sufragar personal y profesionalmente hipotecas vitalicias, el recurrir a lo que algunos han llamado "la ingeniosidad humana" 113 (como por ejemplo, técnicas de desinformación a priori con nombres o cuentas falsas) o cualquier otro retroceso en el camino allanado en materia de igualdad y justicia; como sería el permitir, por omisión, que solo aquellos con determinado poder adquisitivo puedan pagar por solicitar 'desaparecer' de la Red (como lleva pasando años atrás). Esto es intolerable, pues se debería asegurar a todas las personas una garantía para el control efectivo de sus datos personales, de su identidad, y como estudiábamos con Nietzsche y Rousseau, su vida, su libertad y la búsqueda de su felicidad, valores atribuidos al constitucionalismo americano, pero igualmente amparados en el europeo. Así, el derecho al olvido se ha convertido en garantía imprescindible para la protección de datos, los demás derechos fundamentales, y en última instancia, como garantía sin la cual no es verdaderamente realizable la libertad, ni es concebible la dignidad.

Se requiere pues que la regulación y la aplicación de los derechos y garantías digitales se haga desde una ética y perspectiva de los derechos humanos ${ }^{114}$. Además, ello requiere encontrar un justo equilibrio para la ponderación efectiva y la protección de los intereses en juego; por ello proponemos dos derechos al olvido en función de la necesidad de un absoluto borrado y en función de la necesidad de que la información quede menos accesible $^{115}$. Asimismo, se requiere hacer uso de los modelos ya proporcio-

112 Id., pp. 296-297.

113 A. ROUVROY e Y. POULLET, "The right to informational self-determination and the value of self-development: Reassessing the importance of privacy for democracy" en S. GUTWIRTH, Y. POULLET, P. DE HERT, C. DE TERWANGNE y S. NOUWT (eds.), Reinventing Data Protection?, Springer, Dordrecht, 2009, pp. 45-76.

114 L.Q. VILLACORTA MANCEBO y A. VILLACORTA CAÑO-VEGA, Nuevas dimensiones de protección asumidas por los derechos fundamentales, Dykinson, Madrid, 2013, p. 41: "antes los derechos fundamentales solo valían según la medida de las leyes, hoy las leyes solo valen en la medida de los derechos fundamentales".

115 Así lo he hecho en M. MARTÍNEZ LÓPEZ-SÁEZ, La garantía del derecho al olvido: protección de datos, retos futuros y propuestas de regulación de situaciones de vulnerabilidad en la Unión 
nados al respecto, adaptándolos a las exigencias propias del olvido y de los intereses contrapuestos a favor de la memoria. Si bien el derecho al olvido se concibe como un derecho reactivo (pues se ejerce a posteriori del tratamiento de la información personal), que también puede concebirse como derecho y garantía protectora, mediante la cual la supresión de cierta información, tras el trascurso del tiempo, se deja pactada a priori: el principio de minimización del tratamiento y la privacidad (y el olvido) desde el diseño y por defecto en materia de plazos de retención (y en conexión con el principio de limitación de la finalidad y del periodo de conservación), conceptos ya existentes, son mecanismos adecuados para paliar las consecuencias descritas en estas páginas.

En cuanto al principio de minimización exige que los datos sean adecuados, pertinentes y limitados a lo necesario en relación con los fines para los que son tratados (art. 5.1(c) RGPD y art. 11(b) LOPDGDD), quedando deslegitimado cualquier tratamiento incompatible con la finalidad inicial por la que se recogieron los datos personales. De tal modo, la finalidad con la que se recaban y se tratan datos de carácter personal se convierte en legitimación y limitación del tratamiento a la vez. Ello conecta directamente con el derecho al olvido, a través de la jurisprudencia constitucional española: "el tratamiento de los datos debe limitarse únicamente a su propósito $y$ los interesados deben conservar un control efectivo sobre sus propios datos [...] el principio de minimización de datos conecta con el denominado "derecho al olvido" (Sentencia TC 292/2000, de 30 de noviembre) poder eliminar el rastro virtual dejado en el uso de la red, por ejemplo, el perfil en una determinada red social"116. En cuanto a la privacidad/protección de datos por diseño y por defecto, como estrategias básicas enfocadas en la proactividad y prevención en vez de la reactividad y corrección, serían sumamente útiles y garantistas en su aplicación hacía un olvido o inaccesibilidad "forzados" tras cierto periodo de tiempo.

Bajo las anteriores premisas, y ante las preocupaciones sobre el impacto y aumento de los riesgos potenciales para los derechos fundamentales, nacieron los intentos -y posteriores éxitos- de reconocer el derecho al olvido en Europa y nace la inquietud intelectual por perfilarlo, de manera especial,

Europea, Tesis doctoral, Universidad de Valencia, Valencia, 2020.

116 J.R. SAURA, P.R., PALOS SÁNCHEZ, y F.R. DEBASA NAVALPOTRO, “El problema de la reputación online y motores de búsqueda: Derecho al olvido", Cadernos de dereito actual, núm. 2018, p. 226.

DERECHOS Y LIBERTADES

ISSN: 1133-0937

Número 46, Época II, enero 2022, pp. 177-211

DOI: https://doi.org/10.20318/dyl.2022.6518 
en atención a aquellas personas que más necesitan no quedar ancladas en el pasado, ni ser sometidas a cadenas (ni condenas) digitales perpetuas. El presente ensayo pretendía dar una perspectiva de reflexión filosófica sobre el olvido, precisamente aprovechando la existencia de este nuevo derecho en el contexto digital. Se trata de contribuir a hacer de nuestra sociedad virtual, que es igualmente real, un mundo más digno "más justo, más solidario, y en definitiva, más humano" ${ }^{117}$.

\author{
Mónica Martínez LóPeZ-SÁez \\ Universitat de València \\ Avenida de los Naranjos s/n \\ 46022 Valencia \\ e-mail: Monica.martinez-lopez@uv.es
}

117 J.M. GUTIÉRREZ DÍAZ, Proyección práctica de la dignidad humana....cit., p. 95. 